\title{
Next Generation Water Recovery for a Sustainable Closed Loop Living
}

\author{
Santosh H. Vijapur, ${ }^{1}$ Timothy D. Hall, ${ }^{2}$ EJ Taylor, ${ }^{3}$ Danny Liu, ${ }^{1}$ and Stephen Snyder ${ }^{4}$ \\ Faraday Technology Inc., Englewood, OH 45315 \\ and \\ Delmaliz Barreto Vazquez, ${ }^{5}$ Wilfredo Cardona, ${ }^{5}$ Arnulfo Rojas Perez, ${ }^{6}$ and Carlos R. Cabrera ${ }^{7}$ \\ University of Puerto Rico, Rio Piedras Campus, San Juan, PR 00925
}

\begin{abstract}
The water recovery system (WRS) within the Environmental Control and Life Support System (ECLSS) for the International Space Station (ISS) recovers and recycles up to $90 \%$ water from human waste. However, the WRS has lifetime/durability limitations requiring the supply of hazardous chemicals and filter units to treat the system components to maintain their targeted performance. Therefore, next-generation systems are required to reduce waste, enhance water recoverability, and improve process efficiency. Accordingly, Faraday Technology and the University of Puerto Rico (UPR) are developing a bio-electrochemical system to efficiently treat urine waste streams to improve the water recovery system's efficiency/durability by eliminating the hard to remove urea ( 2\%) component from the waste water. Within the bio-electrochemical system, a bioreactor will convert urea from the waste water to ammonia by hydrolysis: $\mathrm{NH}_{2}(\mathrm{CO}) \mathrm{NH}_{2}+\mathrm{H}_{2} \mathrm{O} \rightarrow 2 \mathrm{NH}_{3}+\mathrm{CO}_{2}$. Next, the bioreactor effluent will travel through an ammonia electrolyzer reactor: $2 \mathrm{NH}_{3} \rightarrow \mathrm{N}_{2}+3 \mathrm{H}_{2}$, thus, generating urea/ammonia free waste water effluent. Within this activity, we have (1) leveraged existing knowledge to design and test the bio-electrochemical reactor; (2) explored the efficacy of ( $P$. Vulgaris) bacteria for bioreactor, (3) evaluated electrocatalyst for ammonia reactor, (4) optimized the efficiency and waste water treatment rate with urine simulants. By doing so, we have demonstrated the potential to achieve nearly $100 \%$ ammonia removal during optimized operation. Herein, we will discuss the optimization and scaling of ammonia electrolyzer reactor where a sister paper within the ICES 2021 symposium (ICES-2021-402, ICES300 session) will focus on the bioreactor for this activity. Specifically, we will discuss the results from a bench scale system that provided the information required to design and build a demonstration-scale electrolyzer capable of removing ammonia from $6 \mathrm{~L}$ of urine per day (NASA-STD-3001 Vol 2). The next step for this activity will be a zero-gravity flight test scheduled for May 2021 such that the technology can be validated in microgravity. Establishing the potential to enable compatibility with the existing ECLSS infrastructure and become an integral part of the closed loop living systems required for long term life support on National Aeronautics and Space Administration (NASA)'s manned space missions.
\end{abstract}

\section{Nomenclature}

ANOVA $\quad=$ Analysis of Variance

$B S H U=$ Basal Synthetic Human Urine

DOE $\quad=$ Design of Experiment

${ }^{1}$ Principal Scientist, Faraday Technology Inc., Englewood, OH 45315.

${ }^{2}$ Lab Manager, Faraday Technology Inc., Englewood, OH 45315.

${ }^{3}$ Founder \& Chief Technology Officer, Faraday Technology Inc., Englewood, OH 45315.

${ }^{4}$ Senior Research Engineer, Faraday Technology Inc., Englewood, OH 45315.

${ }^{5} \mathrm{PhD}$ Candidate, University of Puerto Rico, Rio Piedras Campus, San Juan, PR 00926.

${ }^{6}$ Postdoctoral Researcher, University of Puerto Rico, Rio Piedras Campus, San Juan, PR 00926.

${ }^{7}$ Professor, University of Puerto Rico, Rio Piedras Campus, San Juan, PR 00925. 


$\begin{array}{ll}\text { ECLSS } & =\text { Environmental Control and Life Support System } \\ E S H U & =\text { Enriched Synthetic Human Urine } \\ I C E S & =\text { International Conference on Environmental Systems } \\ I S E & =\text { Ion Selective Electrode } \\ I S S & =\text { International Space Station } \\ M F C & =\text { Microbial Fuel Cells } \\ M M O & =\text { Mixed Metal Oxide } \\ N A S A & =\text { National Aeronautics and Space Administration } \\ p p i & =\text { Pores Per Inch } \\ P t & =\text { Platinum } \\ P . v u l g a r i s & =\text { Proteus Vulgaris } \\ T i & =\text { Titanium } \\ U P A & =\text { Urine Processor Assembly } \\ U P R & =\text { University of Puerto Rico } \\ V C D & =\text { Vapor Compression Distillation } \\ W R S & =\text { Water Recovery System }\end{array}$

\section{Introduction}

$\mathrm{A}_{\text {technological advances }}^{\text {MONG the numerous }}$ sought in order to facilitate human space travel, solutions and innovations are needed for techniques that support the mass- and energy-efficient maintenance of closed air, water, and waste systems in spacecraft habitats that operate on planetary environments such as Mars and within microgravity. The system that manages the waste treatment, water recovery, fire detection/response, air revitalization, pressure control, and extra vehicular

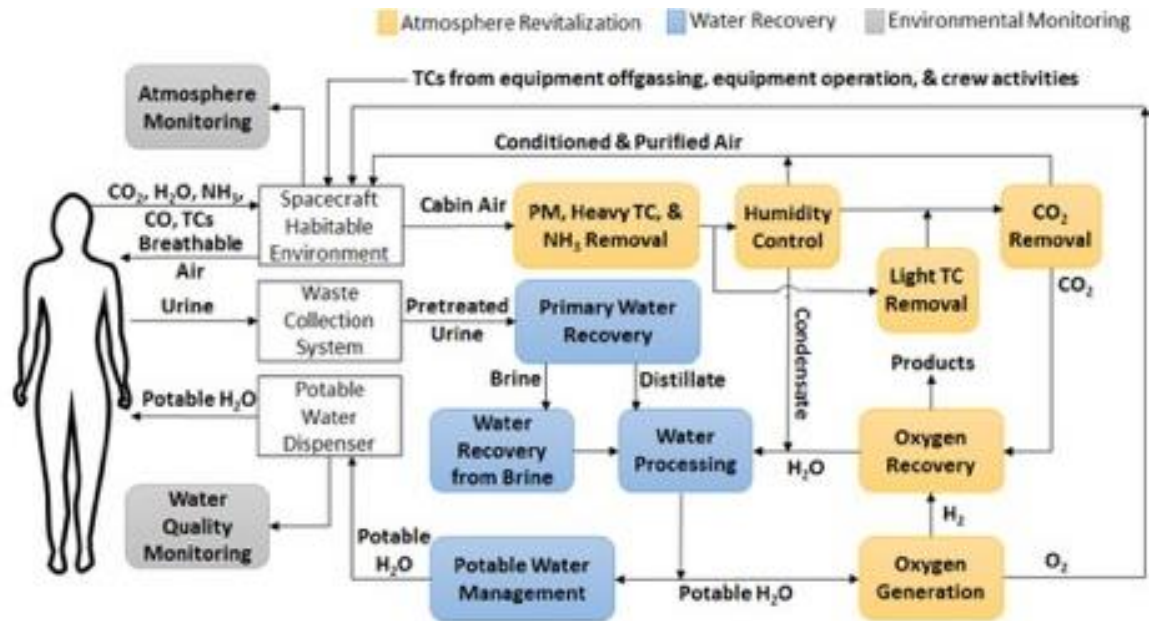

Figure 1. Life Support System Architecture for the ISS. ${ }^{2}$ activities for National Aeronautics and Space Administration (NASA) mission is called the Environmental Control and Life Support System (ECLSS) shown in Figure 1 and is currently able to meet the set of requirements for the given mission duration with the availability of ground support. ${ }^{1,2}$ As missions are foreseen to be extended with the potential for earth resupply being diminished, the ECLSS will need to become a more durable/sustainable closed loop living system that has less reliance on ground support. Therefore, NASA is seeking innovations for effective selfsustainable systems for closed loop living applications. One such area of interest is to improve the efficiency and durability of water recovery system (WRS) within the ECLSS. Current systems require ground support to maintain and only recover about $90 \%$ of the water under peak operation, but their efficiency decreases throughout their lifetime due to unmanageable process contaminants from onboard inhabitants. ${ }^{1,3-5}$ Therefore, to enable manned interplanetary space missions or colonization to be practical it is imperative to create state of the art durable and efficient processes to reduce the impact of contaminants on the waste water treatment system efficiency. In order to achieve NASA's goals of extended manned deep space missions, Faraday Technology and the University of Puerto Rico (UPR) are demonstrating the potential of a bio-electrochemical system to efficiently treat liquid human waste streams such that the potable water recovery system's efficiency/durability can be improved, as shown in Figure 2.6,7 The paper discussed herein will focus on the electrochemical (ammonia reactor) aspect of the bio-electrochemical system while a paper submitted to International Conference on Environmental Systems (ICES) 2021 (ICES-2021-402, ICES300 session $)^{8}$ from our colleagues at the University of Puerto Rico will focus on the biochemical aspects of the approach.

International Conference on Environmental Systems 


\section{A. Background to Water Recovery on ISS}

The functions of a water recovery system (WRS) include wastewater collection; stabilization and storage; primary processing; secondary processing, including water recovery from brines; post processing, disinfection; and potable water storage (Figure 3). ${ }^{9}$ On the ISS, the state-of-the-art WRS is limited to treating only urine and condensate, which may include hygiene water, laundry water and water recovered from brines and solid wastes. Urine is stabilized through the addition of

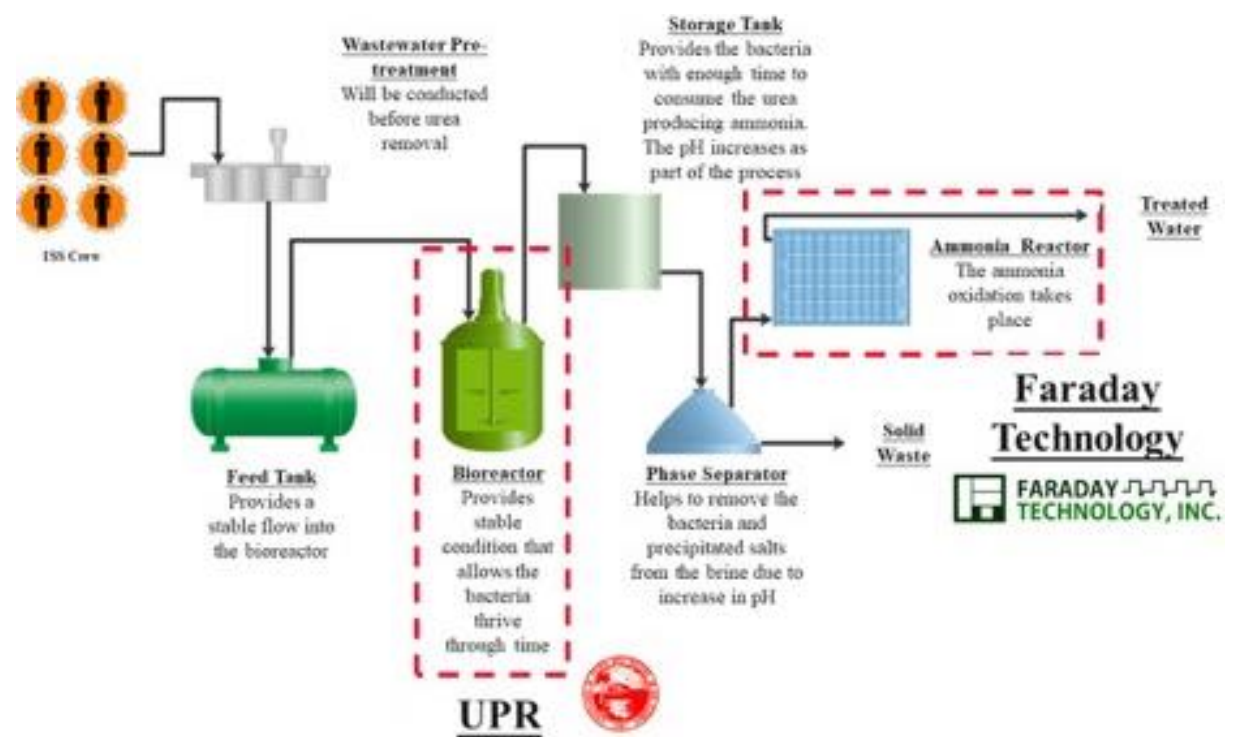

Figure 2. Potential liquid waste treatment platform to reduce ground support and improve water recovery onboard the International Space Station (ISS).

pretreatment chemicals (chromium trioxide and sulfuric acid) at the waste collection system. Water is recovered from the pretreated urine by the Vapor Compression Distillation (VCD) subsystem within the Urine Processor Assembly (UPA). ${ }^{10}$ The UPA was designed to recover $85 \%$ of the water content from the pretreated urine. However, recovery has dropped due to membrane durability and fouling issues.

\section{B. Urea Decomposition to Ammonia}

Urine recycling reduces the cost and satisfies the water demand for NASA's manned space missions. Approximately $95 \%$ of urine is water with $2 \%$ urea. The other components are inorganic salts and organic components that can be removed by reverse osmosis or membranes. However, urea is significantly more difficult to remove and therefore many systems have been proposed and developed to decompose urea based on thermodynamic ${ }^{7}$, chemical ${ }^{9}$ and biological methods. ${ }^{11}$ Biological systems have advantages over other processes due to minimal use of energy and lower operating cost, and utilize microbial enzymes that are more active and stable than plant and animal enzyme systems. ${ }^{12}$ A microorganism that produces the enzyme of interest will result

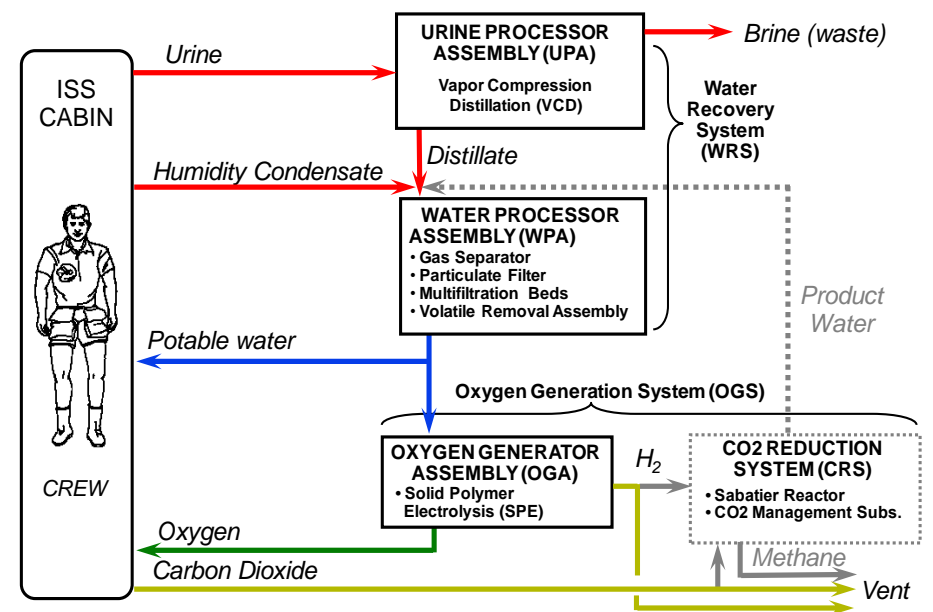

Figure 3. General Architecture of Water Recovery System for the ISS. ${ }^{9}$

in a more stable and self-sustainable system that is compatible with microbial fuel cells (MFC). Prior work has been done for the recovery of nitrogen ${ }^{13}$ and electricity generation from urine ${ }^{14}$ using MFCs but none for water recovery and urine treatment. UPR's bioreactor work has focused on using Proteus vulgaris (P. vulgaris), to create an ureolysis system for urine recycling. The overall reaction can be written as:

$$
\mathrm{NH}_{2}(\mathrm{CO}) \mathrm{NH}_{2}+\mathrm{H}_{2} \mathrm{O} \rightarrow 2 \mathrm{NH}_{3}+\mathrm{CO}_{2}
$$

The $P$. vulgaris bacteria have the ability to produce urease, an enzyme that catalyzes the conversion of urea to ammonia. Later, the ammonia can be oxidized within an electrochemical reactor. ${ }^{15}$ The effluent water from the bioreactor will be screened to eliminate bacteria transference to downstream systems.

International Conference on Environmental Systems 


\section{Electrochemical Oxidation/ Destruction of Ammonia}

The influent ammonia from the bioreactor will then be oxidized/destroyed in an electrolyzer according to the reaction:

$$
2 \mathrm{NH}_{3}+6 \mathrm{OH}^{-} \rightarrow \mathrm{N}_{2}+6 \mathrm{H}_{2} \mathrm{O}+6 \mathrm{e}^{-}
$$

at a standard potential of $-0.77 \mathrm{~V}$ vs. SHE.

While water is simultaneously reduced according to the following reaction:

$$
6 \mathrm{H}_{2} \mathrm{O}+6 \mathrm{e}^{-} \rightarrow 3 \mathrm{H}_{2}+6 \mathrm{OH}^{-}
$$

at a standard potential of $-0.82 \mathrm{~V}$ vs. SHE.

The interactions between these reactions on any given electrode are a complex function of the local conditions, including current density, applied potential, local concentrations, and fluid velocity. Significant research has been performed on this family of reactions, much in the context of fuel cell development, in an effort to gain the understanding required to design highly-efficient power sources and electroreactors. Since factors such as local species concentrations and flow fields are of such importance, the structural design of the electrolytic cell is also critical. A conceptual ammonia electrolyzer reactor configuration is shown in Figure 4.

\section{Experimental}

\section{A. Bioreactor Effluent} Urine Simulant

Within all the trials discussed herein we utilized the base Basal Synthetic Human Urine (BSHU) with amino acids and glucose that was previously demonstrated as an adequate urine simulant. ${ }^{16,17}$ In this case the urine simulant was prepared as if $90 \%$ of the urea had been converted to ammonia within the bioreactor (or some other upstream process), thus simulating an efficiently operating bioreactor. Therefore, the BSHU was prepared as listed in Table 1 (at 90\% urea consumption). Each compound was added independently and allowed to dissolve in deionized water and adjusted to $\mathrm{pH} 9$ (the anticipated $\mathrm{pH}$ leaving the bioreactor). As prepared BSHU was filtered with a $1 \mu \mathrm{m}$ pore filter (Fisher Scientific Company), and aliquots were stored at $4^{\circ} \mathrm{C}$ until use.

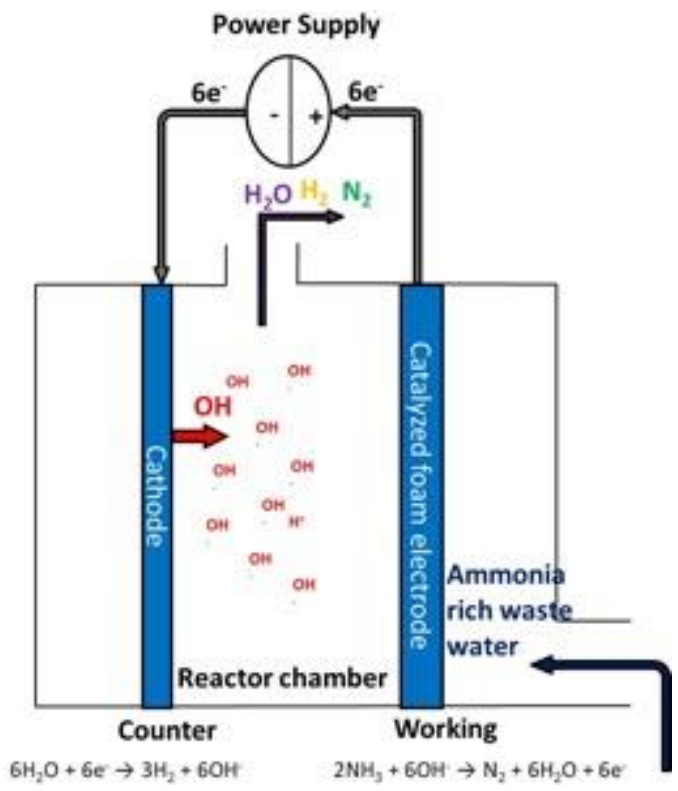

Figure 4. Conceptual ammonia electrolyzer reactor for ammonia oxidation.
Table 1. Basal Synthetic Human Urine (BSHU) with amino acids and glucose

\begin{tabular}{|c|c|c|c|c|}
\hline Constituent & $\begin{array}{l}\mathrm{SHU} \\
(\mathrm{mM})\end{array}$ & $\begin{array}{c}\text { Amount per } 1 \mathrm{~L} \\
\text { (g) }\end{array}$ & Amino Acids & $\begin{array}{c}\text { Amount per 1L } \\
\text { (g) }\end{array}$ \\
\hline $\mathrm{NaCl}$ & 100 & 5.844 & Aspartic Acid & 0.00976 \\
\hline $\mathrm{Na}_{2} \mathrm{SO}_{4}$ & 17 & 2.4147 & Threonine & 0.0194 \\
\hline Urea & 280 & 1.68 & Serine & 0.04231 \\
\hline & & & Glutamic Acid & 0.00718 \\
\hline & 50 & 2.0007 & Valine & 0.00745 \\
\hline $\mathrm{CaCl}_{2}$ dillyarate & 4 & 0.4439 & Methionine & 0.00462 \\
\hline Creatinine & 9 & 1.0181 & Leucine & 0.00861 \\
\hline Sodium citrate & 3.4 & 1.9999 & Tyrosine & 0.04186 \\
\hline $\mathrm{NH}_{4} \mathrm{Cl}$ & 20 & 28.02 & Phenylalanine & 0.01403 \\
\hline $\mathrm{MgSO}_{4}$ heptalyydrate & 3.2 & 0.7887 & Histidine & 0.16915 \\
\hline Sodium oxalate & 0.18 & 0.0241 & Lysine & 0.01923 \\
\hline Sodium phosphate monobasic & 3.6 & 0.5616 & Proline & 0.00452 \\
\hline Sodium phosphate dibasic & 6.5 & 0.9227 & Glycine & 0.14112 \\
\hline Potassium phosphate monobasic & 16 & 2.1774 & Alanine & 0.04291 \\
\hline Uric acid & 0.6 & 0.1009 & Isoleucine & 0.00818 \\
\hline Sodium bicarbonate & 13.5 & 1.1341 & Cystine & $\frac{0.11117}{0.02397}$ \\
\hline
\end{tabular}
after $90 \%$ consumption of the urea within the bioreactor.

International Conference on Environmental Systems 


\section{B. Ammonia Detection}

Ammonia present in the electrolyte was measured using a Thermo Scientific Orion Dual Start $\mathrm{pH} / \mathrm{ISE}$ meter equipped with an ammonia Ion Selective Electrode (ISE). Figure 5 shows the calibration curve developed using the as prepared BSHU simulant diluted to produce specific concentrations. The ISE measurement works by taking an aliquot of the simulant adding $\sim 1 \mathrm{~mL}$ of ISE solution and $2 \mathrm{~mL}$ of $10 \mathrm{M} \mathrm{NaOH}$ to increase the $\mathrm{pH}$ above 14. A hydrophobic gas-permeable membrane in the ISE separates the sample solution from the electrode filling solution. ${ }^{18}$

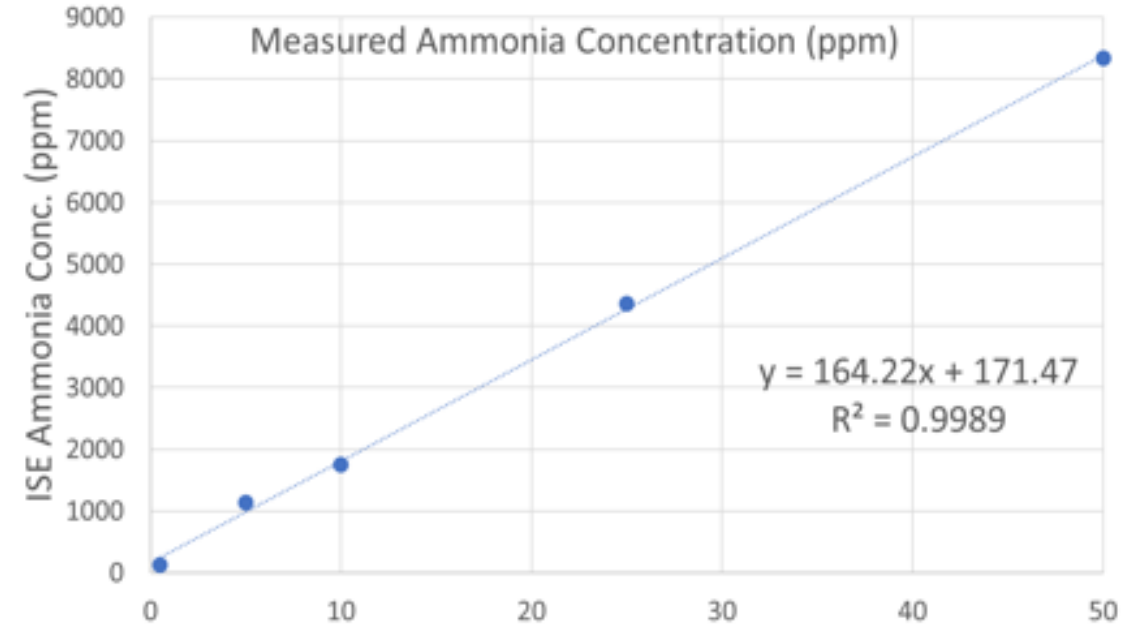

Volume of Syn. Urine added to $50 \mathrm{~mL}$ Vol. Flask $(\mathrm{mL})$

Figure 5. Concentration profile of Ammonia as measured by an ion selective electrode (ISE).

Dissolved ammonia in the sample solution diffuses through the membrane until partial pressure equilibrates. ${ }^{18}$ In any given sample the partial pressure of ammonia will be proportional to its concentration. ${ }^{18}$

\section{Ammonia Oxidation/Destruction Reactor}

At the onset of the activity, we designed and built ammonia reactor (Figure 6) comprised of stack of cells with a liquid electrolyte-filled gap ( 0.37 in.) between the anode and the cathode. The reactor consists of graphite working electrode plate with inlet manifold, a central reactor chamber ( 0.37 in. thick) with an outlet manifold, and a graphite counter electrode plate. Anode and cathode electrocatalytic electrodes were pressed against the electrode plates. The electrocatalytic electrodes were either platinum $(\mathrm{Pt})$ foil or were prepared by platinizing a titanium (Ti) foam support (Selee Corporation) via an electrodeposition approach from a commercially available Pt Q-Salt plating electrolyte (Johnson Mathey), as discussed within the next section. Figure 6 shows the electrochemical reactor configuration where the screened bioreactor effluent enters through the anode's (working electrode) fluid manifold travels through the electrocatalyzed electrode and exits with the reaction byproducts through the center channel. When the electrical current is applied to the cell, ammonia is oxidized to nitrogen and water at the anode catalyst interface. The bulk of the solution flows through the cell and into the exit

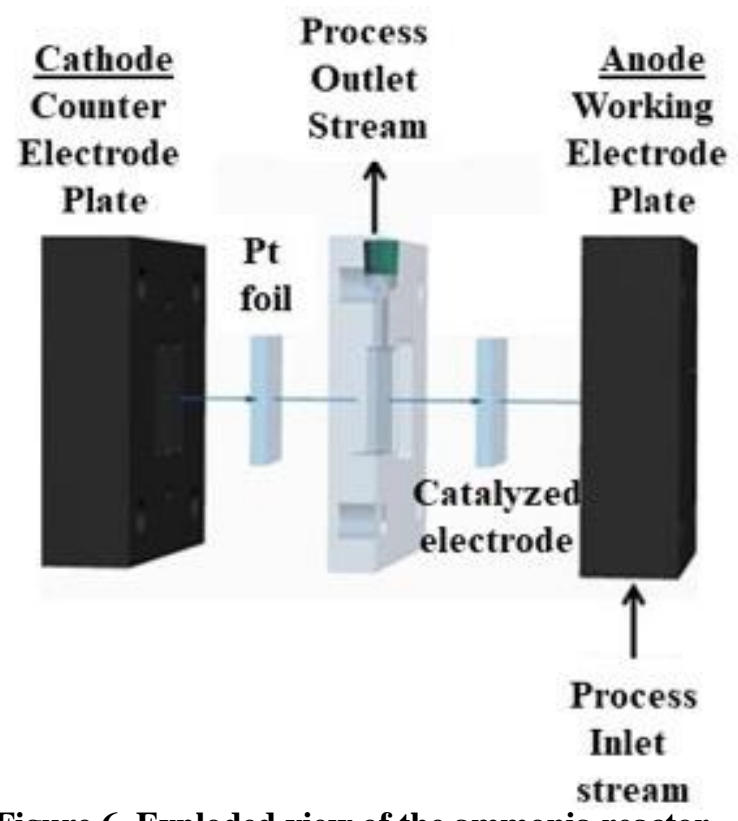

Figure 6. Exploded view of the ammonia reactor.

manifold. The reactor was powered via a dedicated power supply.

\section{Electrode Fabrication}

Platinum was electrochemically deposited in a beaker cell containing a solution of Platinum Q Salt ${ }^{\circledR}$ ( $\left[\mathrm{Pt}\left(\mathrm{NH}_{3}\right)_{4}\right]\left(\mathrm{HPO}_{4}\right)$, Johnson Matthey), diluted from Pt 20Q to Pt 5Q. Deposition proceeded with 60 or 80 pores per inch (ppi) Ti foam (Figure 7 top) working electrode which was surrounded by a cylindrical mixed metal oxide (MMO) counter electrode mesh. The typical geometric active area was estimated from the dimensions of the rectangular Ti foam and ranged from approximately $20-22 \mathrm{~cm}^{2}$. Electrodeposition occurred at a constant current of $1 \mathrm{~A}$ with a bath temperature of $70-75^{\circ} \mathrm{C}$. The electrodes were prepared with a platinum loading of about $70 \mathrm{mg} / \mathrm{cm}^{2}$ (Figure 7 bottom).

International Conference on Environmental Systems 


\section{Results and Discussion}

\section{A. Bench-Scale Ammonia Reactor Performance}

We performed ammonia oxidation trials in the flow through cell with $\mathrm{Pt} / \mathrm{Ti}$ foam electrodes to investigate its potential performance towards ammonia oxidation and evaluate stability of the Ti foam. For this set of trials, we utilized the following process parameters:

- Pass - Multi pass (continuous recirculation of the electrolyte into a single reservoir)

- Electrolyte - $50 \mathrm{~mL}$ simulant bioreactor effluent (Table 1)

- Flow rate $-20 \mathrm{~mL} / \mathrm{min}$

- Operating Temperature $-20^{\circ} \mathrm{C}$

- Anode - Platinized Ti foam (60 ppi and 80 ppi) @ $\sim 70 \mathrm{mg} / \mathrm{cm}^{2}$

- Cathode - Pt foil

- Experiment duration $-2 \mathrm{~h}$

Figure 8 shows that the ammonia conversion increased with an increase in the applied cell potential during constant experiment duration (2h). However, no other significant differences in the performance were observed when comparing the two $\mathrm{Ti}$ foam supports, indicating low cell voltages are sufficient to remove ammonia from the bioreactor effluent.

We also investigated the effect of process duration at constant applied cell potential. The following conditions were used in the study:

- Pass - Multi pass (continuous recirculation of the electrolyte into a single reservoir)

- Electrolyte - $50 \mathrm{~mL}$ simulant bioreactor effluent (Table 1)

- Flow rate $-20 \mathrm{~mL} / \mathrm{min}$

- Operating Temperature $-20^{\circ} \mathrm{C}$

- Anode - Platinized Ti foam (60 ppi and $80 \mathrm{ppi}) @ \sim 70 \mathrm{mg} / \mathrm{cm}^{2}$

- Cathode - Pt foil

- Applied cell potential - 6 V

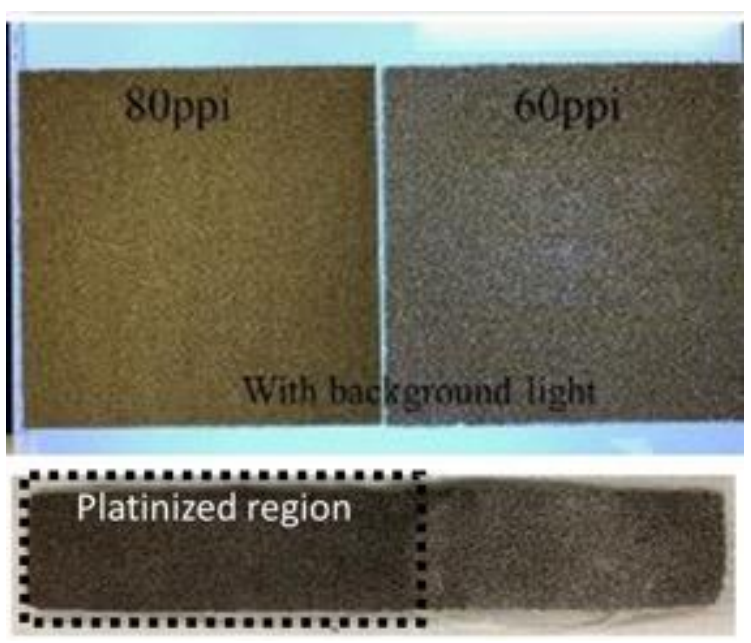

Figure 7. Titanium foams with different porosity procured from Selee Corporation (top); Platinized titanium foam (bottom).

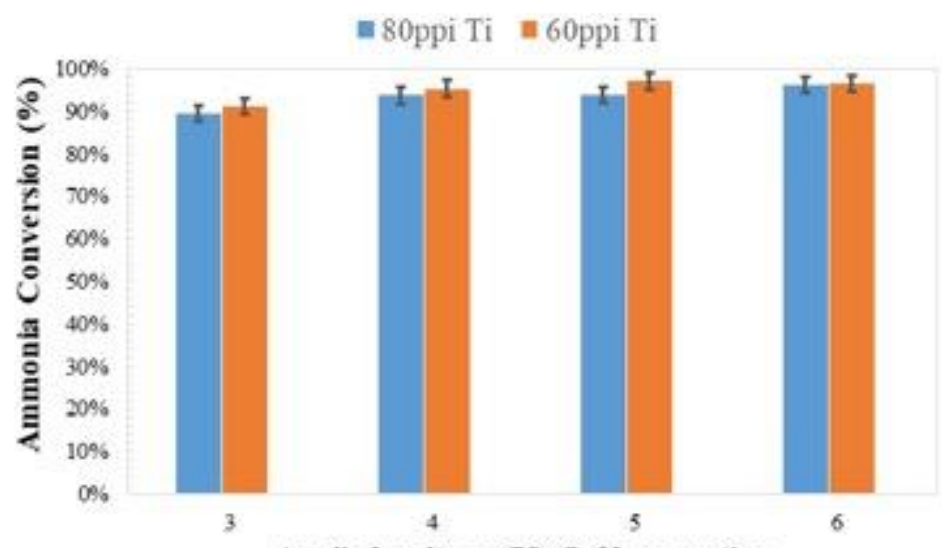

Applied voltage (V) @ 2h operation

Figure 8. Ammonia oxidation during constant experiment duration/differential cell potential trials using $50 \mathrm{~mL}$ BSHU as electrolyte demonstrates increase in ammonia oxidation as the applied cell potential is increased.

Figure 9 showed that the ammonia conversion increased with longer experimental duration at constant applied cell potential $(6 \mathrm{~V})$. However, no significant difference in the performance was observed when comparing the two Ti foam supports.

Trials were also conducted to evaluate the stability of the Ti foam electrodes. The above-mentioned processing conditions were used by changing the following parameters:

- Applied cell potential $-6 \mathrm{~V}$

- Experiment duration $-4 \mathrm{~h}$

The electrodes were observed to be stable after the $4 \mathrm{~h}$ polarization trial. Moreover, complete ammonia conversion $(<0.1 \mathrm{ppm})$ was achieved. No measurable difference in performance was observed between the two electrodes. (See Figure 10.)

International Conference on Environmental Systems 
Based on the above, process optimization was performed in the system to investigate various performance parameter via a design of experiments (DOE), the variables tested include:

- Applied potential: 4, and $6 \mathrm{~V}$

- Flow rate: 10 and $20 \mathrm{~mL}$ per min

- Operating temperature: 20 and $40^{\circ} \mathrm{C}$

- Processing time: 60 and $120 \mathrm{~min}$

- Orientation: Pt Ti 80ppi Anode/ Pt foil cathode; Pt Ti 80ppi Anode/MMO cathode; MMO Ti 80ppi Anode/Pt foil cathode

$50 \mathrm{~mL}$ BSHU with amino acids and glucose (Assuming 90\% conversion of Urea to $\mathrm{NH}_{3}$ ) was used as electrolyte for each trial. Ammonia concentration was measured by ion selective electrode at the completion of each trial. Optimized conditions will aid in designing and building an alpha scale ammonia reactor that will be assessed in terms of ammonia oxidation performance in zero-gravity. Minitab was employed to perform Analysis of Variance (ANOVA) to analyze the results of these trials through the production of main effects and interaction plots with respect to processing variables and the percentage of ammonia converted (Figure 11 and Figure 12). The study indicated that as the applied cell potential and process time increased the ammonia conversion increased. Furthermore, operating the electrochemical cell at $40^{\circ} \mathrm{C}$ increased the ammonia conversion. The flow rate was observed to have insignificant effect on ammonia conversion. The system setup orientation with respect to anode and cathode materials demonstrated a measurable effect in the percentage of ammonia conversion. Where the MMO as anode in MMO/Pt configuration has lower conversion efficiencies than Pt as anode in Pt/MMO. This is attributed to the high catalytic activity of Pt towards ammonia oxidation. Additionally, lower ammonia conversion was observed when using the $\mathrm{Pt} / \mathrm{Pt}$ configuration which might be attributed to precipitation/surface blockage on the Pt foil counter during operation. We believe these surface blockages can be prevented by operating the cell using pulse/pulse reverse conditions.

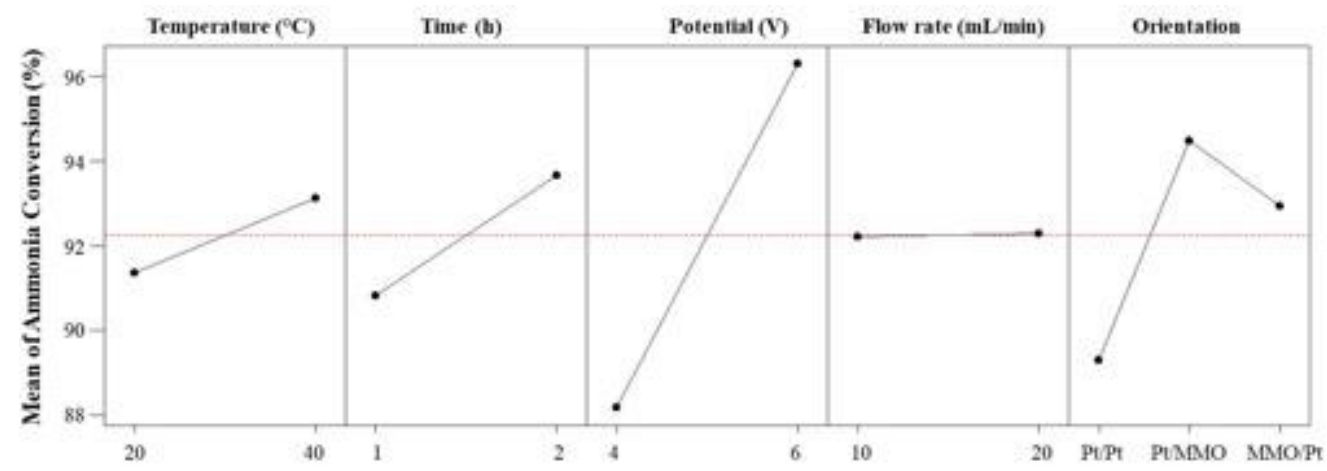

Figure 11. Ammonia conversion as a function of the various process variables evaluated in the DOE; where the red line represents the mean of the $\mathbf{4 8}$ individual data points collected.

International Conference on Environmental Systems

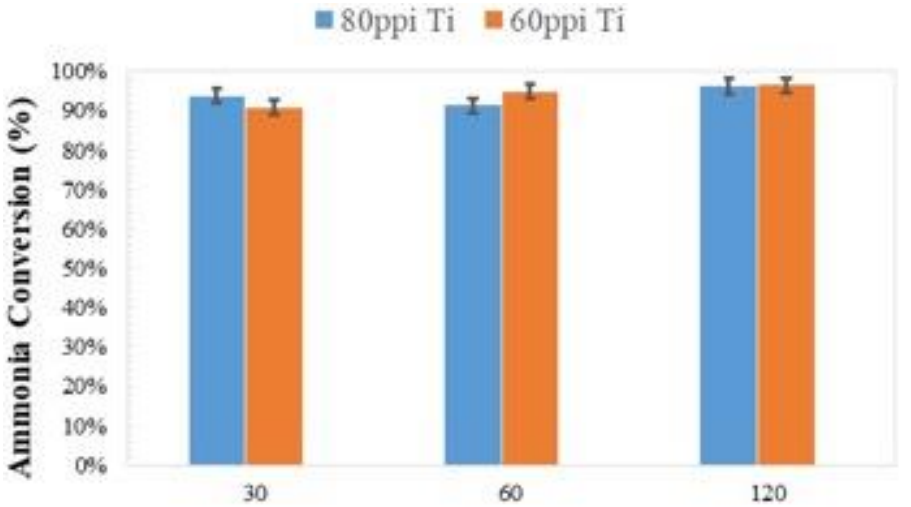

Polarization time (min) @6V operation

Figure 9. Ammonia oxidation during constant cell potential/differential experiment duration trials using $50 \mathrm{~mL}$ BSHU as electrolyte demonstrates increase in ammonia oxidation as the experiment duration is increased.

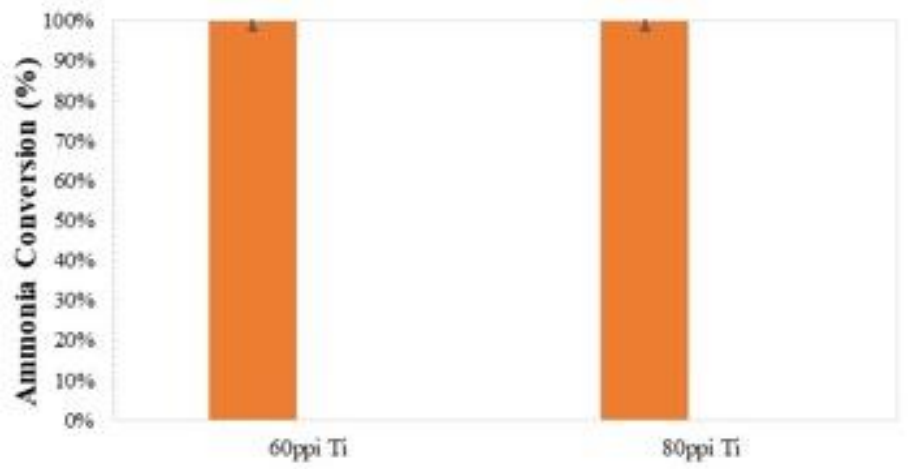

Titanium substrate $@ 6 \mathrm{~V}$ and $4 \mathrm{~h}$ operation

Figure 10. Ammonia oxidation during constant cell potential/ experiment duration trials using $50 \mathrm{~mL}$ BSHU as electrolyte demonstrates complete ammonia conversion. 
The interaction plots show the effect of the interactions of various process control variables on the percentage ammonia converted (Figure 12). The study indicated that operating the reactor at high applied cell potentials for longer experimental durations and higher temperatures increased the percentage of ammonia conversion. The effect of flow rate and the cell orientation consistently shows minimal impact on the percent ammonia conversion.

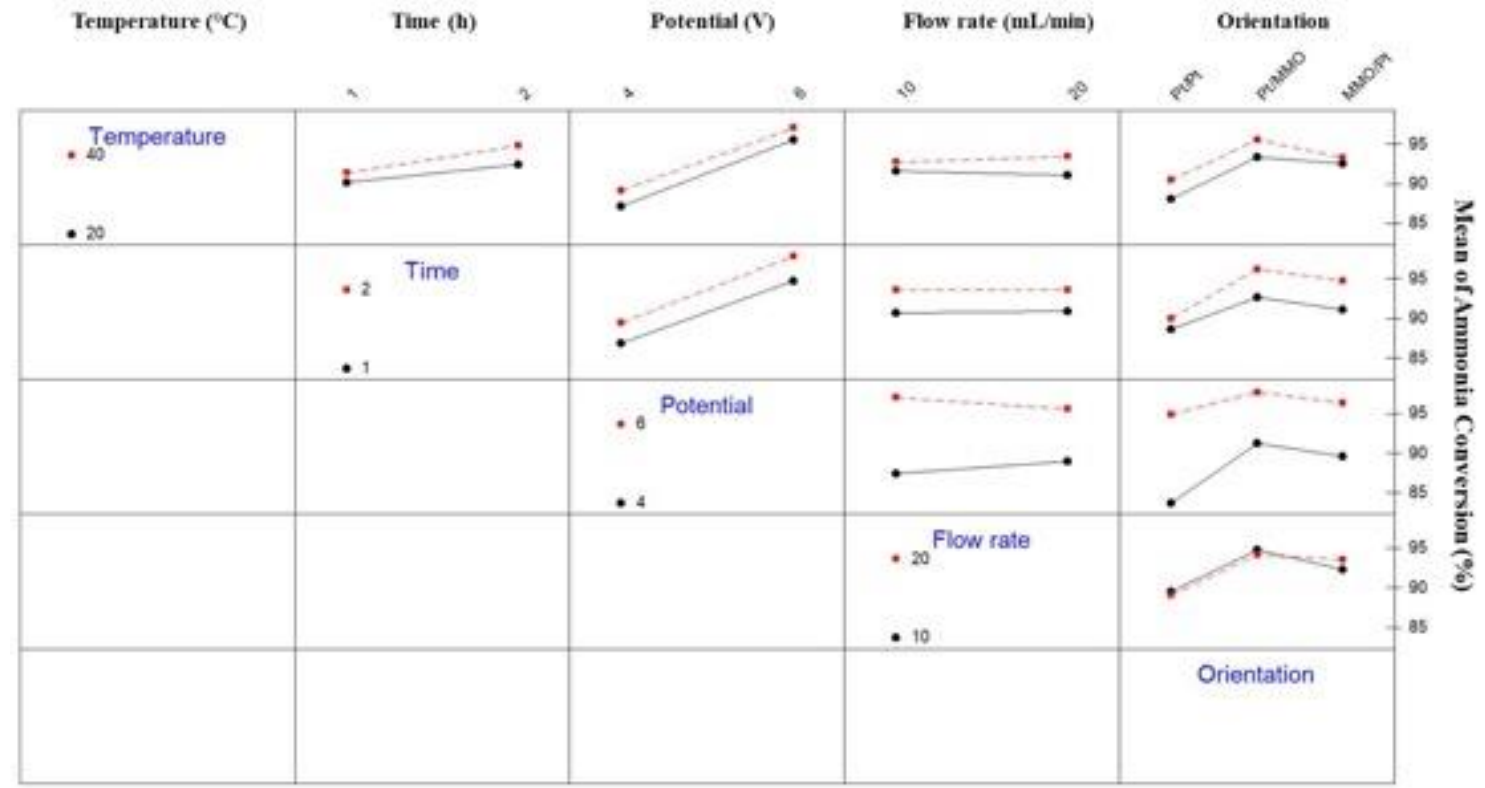

Figure 12. Ammonia conversion as a function of the interaction of various process variables evaluated in the DOE. Where the right $\mathrm{Y}$-axis shows the \% of ammonia conversion and the multiple $\mathrm{x}$-axis show the effect of each operating condition from the DOE. The labeling in the figure also shows the tertiary effect Red and Black for each condition evaluated.

Next, we compared single-pass (continuous flow from a single reservoir) and multi-pass (continuous recirculation of the electrolyte into a single reservoir) polarization trials with the following process parameters:

- Electrolyte $-50 \mathrm{~mL}$ simulant bioreactor effluent (Table 1)

- Flow rate $-1 \mathrm{~mL} / \mathrm{min}$ for single pass and $20 \mathrm{~mL} / \mathrm{min}$ for multi pass

- Operating Temperature $-40^{\circ} \mathrm{C}$

- Anode - Platinized Ti foam (80 ppi) @ 70 mg/cm²

- Cathode - Pt foil

- Potential-6 V

- Experiment duration - 40 min for single pass and 120 min for multi-pass

The single pass trial exhibited lower ammonia conversion than what was observed for the multi-pass configuration (Figure 13). This could be due to the longer residence time of the electrolyte in the reactor where the multi-pass system has $\sim 40 \%$ more exposure time. These results are an indication that the reactor has the potential to operate in a single pass orientation by incorporating an appropriate retention time within the systems operating procedures.

Next, we performed multi-pass polarization trial with $1 \mathrm{~L} \mathrm{BSHU}$ and the following process parameters:

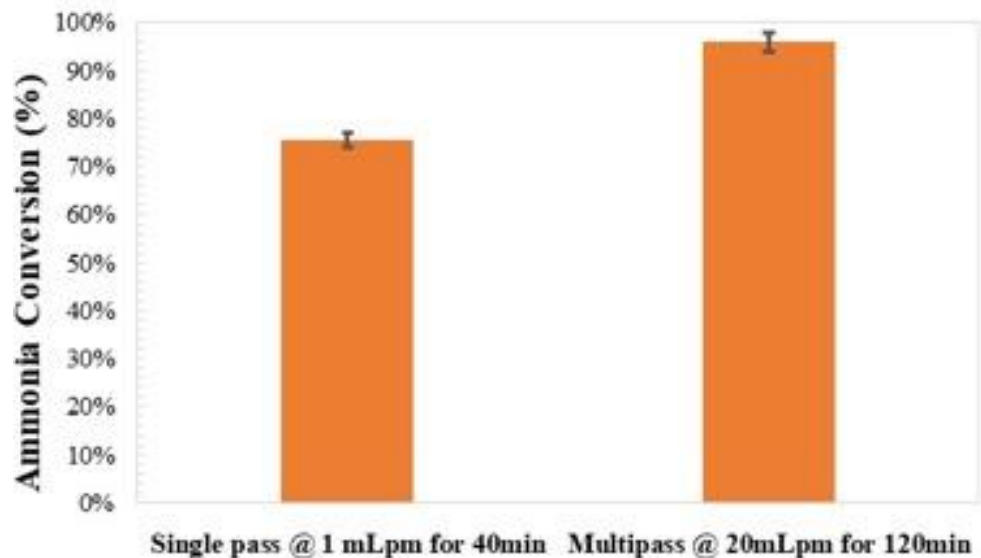

Figure 13. Ammonia conversion observed during single pass trial in comparison to multipass trial.

International Conference on Environmental Systems 
- Flow rate $-20 \mathrm{~mL} / \mathrm{min}$

- Operating Temperature $-40^{\circ} \mathrm{C}$

- $\quad$ Anode - Pt foil or Platinized Ti foam (80 ppi) @ 70 mg/ $\mathrm{cm}^{2}$

- Cathode - Pt foil

- Potential $-6 \mathrm{~V}$

Figure 14 depicts two separate trials of $6 \mathrm{~V}$ electrochemical conversion of $1 \mathrm{~L} \mathrm{BSHU}$ with the anode consisting of Pt foil (orange data points) or platinized Ti foam (blue data points). As a reference, the pristine ammonia concentration, based on the starting $\mathrm{NH}_{4} \mathrm{Cl}$ molar concentration of $0.524 \mathrm{M}$, within the $90 \%$ conversion BSHU, and calculated to be $8,908 \mathrm{ppm}$ ammonia $\left(\mathrm{NH}_{3}\right)$. This reference is plotted as the green data point in Figure 14 .

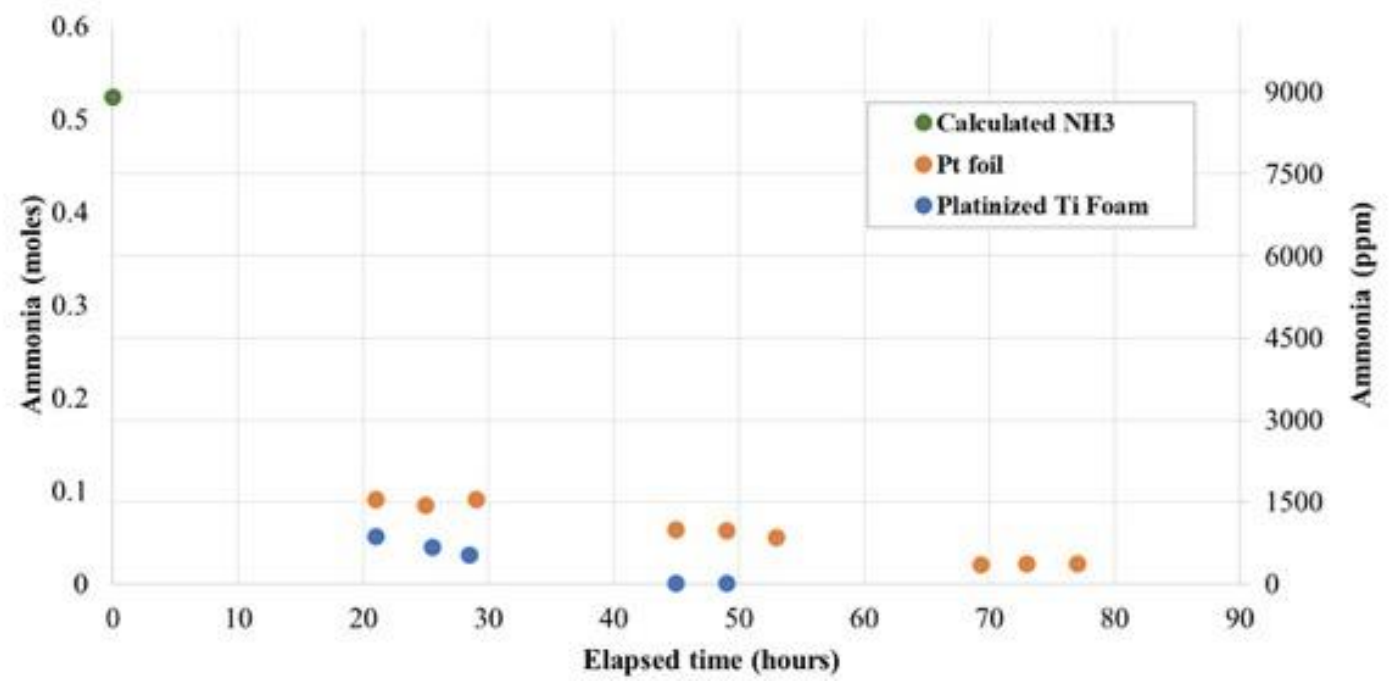

Figure 14. Ammonia concentration in ppm (right axis) determined via ISE from 50 mL aliquots extracted, at periodic intervals, from 1L of BSHU throughout $6 \mathrm{~V}$ electrochemical conversion. The moles of ammonia (left axis) within the $1 \mathrm{~L}$ reservoir was determined by scaling the ISE measured ammonia concentration from $50 \mathrm{~mL}$ to $1 \mathrm{~L}$.

Periodic sampling of the $1 \mathrm{~L}$ solution involved extracting $50 \mathrm{~mL}$ aliquots for ISE analysis, followed by immediate replenishment with $50 \mathrm{~mL}$ of fresh/pristine BSHU (8,908 ppm ammonia). As the electrochemical conversion progressed, the measured ammonia is plotted in Figure 14. For the platinized Ti foam (blue data), the ammonia exhibited a decreasing trend, reaching negligible levels $(<0.1 \mathrm{ppm} ; 100 \%$ reduction in ammonia concentration) after 48 hours of total elapsed time. A similar trend is exhibited for the Pt foil trial (orange data), where the ammonia decreased to approximately 0.02 moles $(\sim 350 \mathrm{ppm} ; 96 \%$ reduction in ammonia concentration) after 69 hours. Comparison of the catalyst performance based on the conversion rate suggests that the platinized Ti foam can convert a given amount of ammonia within a shorter time frame using the $6.25 \mathrm{~cm}^{2}$ system. The difference in performance can be attributed to the surface area of the catalyst. Platinized titanium foam catalyst has high porosity and surface area than bulk Platinum foil and thus demonstrates higher ammonia conversion rates in comparison.

\section{B. Process Scale-Up}

From the performance metrics above we can scale the system to the enable the removal of ammonia from at least 6 L of urine per day. Specifically, we have shown that $1 \mathrm{~L}$ of BSHU with amino acids and glucose can be treated in $48 \mathrm{~h}$ with a $6.25 \mathrm{~cm}^{2}$ electrode at a total power consumption of $\sim 16 \mathrm{~W}(16 \mathrm{~V}$ and $1 \mathrm{~A})$ or $2.5 \mathrm{~W} / \mathrm{cm}^{2}$

If we then assume that the electrode scales linearly, we need to increase the working area from $48 \mathrm{~h}$ electrochemical processing of $1 \mathrm{~L}$ solution with $6.25 \mathrm{~cm}^{2}$ electrode area to $24 \mathrm{~h}$ electrochemical processing of $1 \mathrm{~L} \mathrm{solution} \mathrm{with} \sim 13 \mathrm{~cm}^{2}$ electrode area. Furthermore, to electrochemically process $6 \mathrm{~L}$ solution in $24 \mathrm{~h}$, the required electrode area would then be $\sim 78 \mathrm{~cm}^{2}$. Moreover, from $2.5 \mathrm{~W} / \mathrm{cm}^{2}$ experimental data, we would require $\sim 200 \mathrm{~W}$ to treat $6 \mathrm{~L}$ in $24 \mathrm{~h}$ or $\sim 5 \mathrm{kWh}$ per $6 \mathrm{~L}$ per day urine treatment.

International Conference on Environmental Systems 
Following Table 2 shows the data from the experimental values and scaled up estimates to treat $1 \mathrm{~L}$ and $6 \mathrm{~L}$ of urine per day based upon a linear scale. The large footprint and mass predicted is a conservative estimate and as shown below this is a major over estimate to the size of the as-built system.

Table 2. Scale up estimates based on bench-scale electrolyzer performance.

\begin{tabular}{|c|c|c|c|}
\hline Urine & $\begin{array}{c}1 \mathrm{~L} \\
\text { (Experimental) }\end{array}$ & $\begin{array}{c}1 \mathrm{~L} / \mathrm{day} \\
(\text { Estimated) }\end{array}$ & $\begin{array}{c}6 \text { L/Day } \\
\text { (Estimated) }\end{array}$ \\
\hline Cell Area $\left(\mathrm{cm}^{2}\right)$ & 6.25 & 13 & 78 \\
\hline Total Processing Time (h) & $\begin{array}{l}48 \text { (with Pt/Ti } \\
\text { foam) }\end{array}$ & 24 & 24 \\
\hline Total Mole $\mathrm{NH}_{4}$ removed $(\mathrm{mol})$ & 0.6 & 0.6 & 3.5 \\
\hline Initial theoretical Concentration of $\mathrm{NH}_{3}(\mathrm{ppm})$ & 8908 & 8908 & 8908 \\
\hline Final Concentration of $\mathrm{NH}_{3}(\mathrm{ppm})$ & $<0.1$ & $<0.1$ & $<0.1$ \\
\hline Power Input (kWh/ mole $\left.\mathrm{NH}_{3}\right)$ & 0.5 & 0.5 & 0.5 \\
\hline Footprint $(\mathbf{l} \times \mathbf{x}$ w $x$ h h $)$ & $\begin{array}{l}2.5 \text { in. } x 2 \text { in. } x \\
2.5 \text { in. }\end{array}$ & $\begin{array}{c}5 \text { in. } x 4 \text { in. } x 5 \\
\text { in. }\end{array}$ & $\begin{array}{c}30 \text { in. } x 24 \text { in. } x \\
30 \text { in.* }\end{array}$ \\
\hline Active area $\left(\mathrm{in}^{2} / \mathrm{cm}^{2}\right)$ & $\sim 1 / 6.25$ & $2 / 12.5$ & $12 / 75$ \\
\hline Weight $(\mathbf{k g})$ & 0.3 & 0.6 & 4.0 \\
\hline
\end{tabular}

Initial alpha scale design targets include:

- $6 \mathrm{~L}$ of urine treatment per day

- $\quad 78 \mathrm{~cm}^{2}\left(12 \mathrm{in}^{2}\right)$ working area

- Anolyte chamber with flow field to provide uniform flow distribution

- Anode - with inset for platinized Ti foam or without inset for Pt foil

- Cathode - with inset for platinized Ti foam or without inset for Pt foil

Accordingly, we have designed the alpha scale ammonia reactor system consisting of:

- Total reactor area of 7 in. $x 7$ in. $x 1.25$ in.

- Reactor weight $-3.8 \mathrm{~kg}$

- One cathode and anode chamber which will be titanium block with a central 4 in. $x 4$ in. electrode holding inset for platinized titanium foam electrodes

- One cathode and anode chamber which will be titanium block with a central 4 in. $x 4$ in. for holding the platinum foil electrodes

- PVC anolyte chamber ( $1 / 2$ in., $3 / 8$ in. and $1 / 4$ in. thickness) to incorporate the flow field design with a 4 in. $x 4$ in. central working area

The exploded view of this alpha-scale ammonia reactor is shown in Figure 15, which will be used to demonstrate the potential of treating $6 \mathrm{~L}$ urine per day.
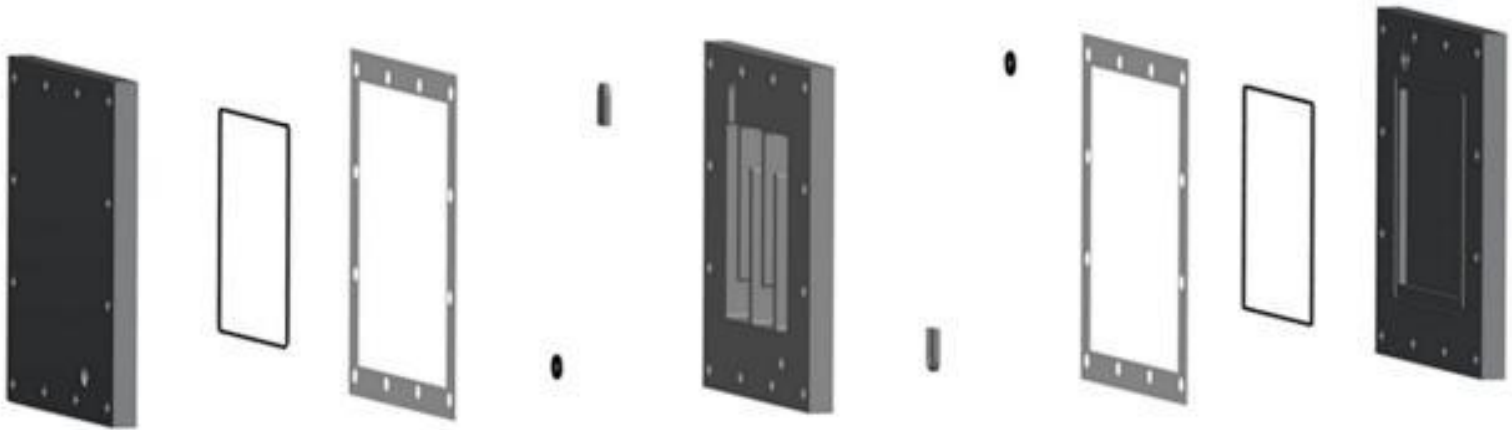

Figure 15. Exploded view of the alpha scale ammonia reactor.

The alpha scale components are -

- Two titanium plates without the inset for the Pt foil/mesh (Figure 16 - Left)

- Two titanium plates with inset for the Ti foams (Figure 16 - center)

International Conference on Environmental Systems 
- Three central PVC reactor chamber with flow field configuration - different thickness: $1 / 2$ in., $3 / 8$ in. and $1 / 4$ in. (Figure 16 - Right)
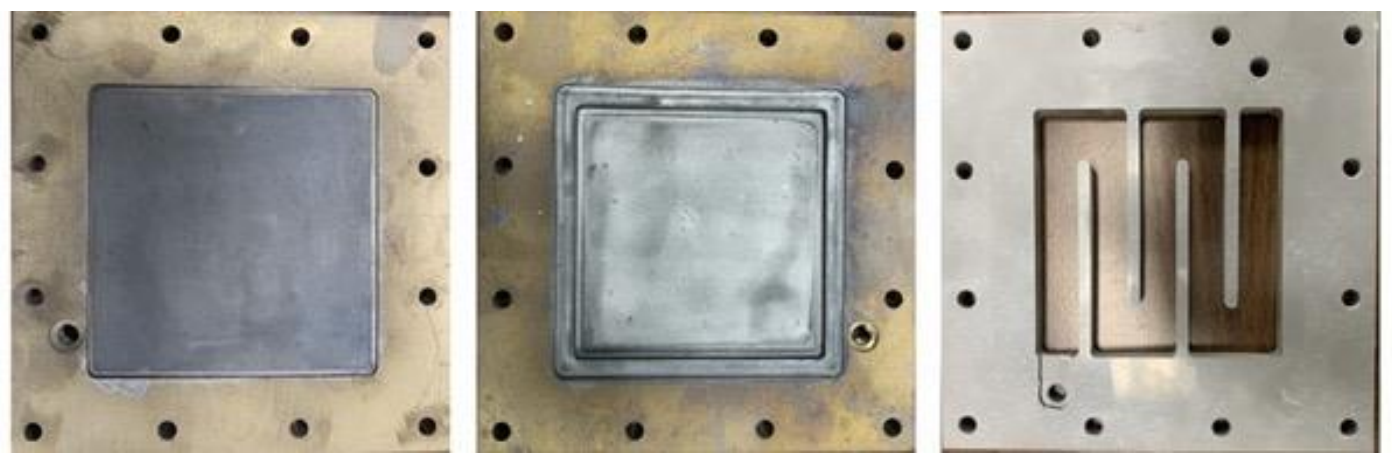

Figure 16. Photograph of alpha scale reactor components received from Republic Anode Fabricators.

Initial trial (Figure 17) with the alpha scale reactor (Pt/Pt foil system) exhibits a potential to achieve higher ammonia conversion rates in comparison to bench-scale reactor ( $\mathrm{Pt} / \mathrm{Pt}$ foil system) at similar operating conditions, which demonstrates the scalability of the system and the process.

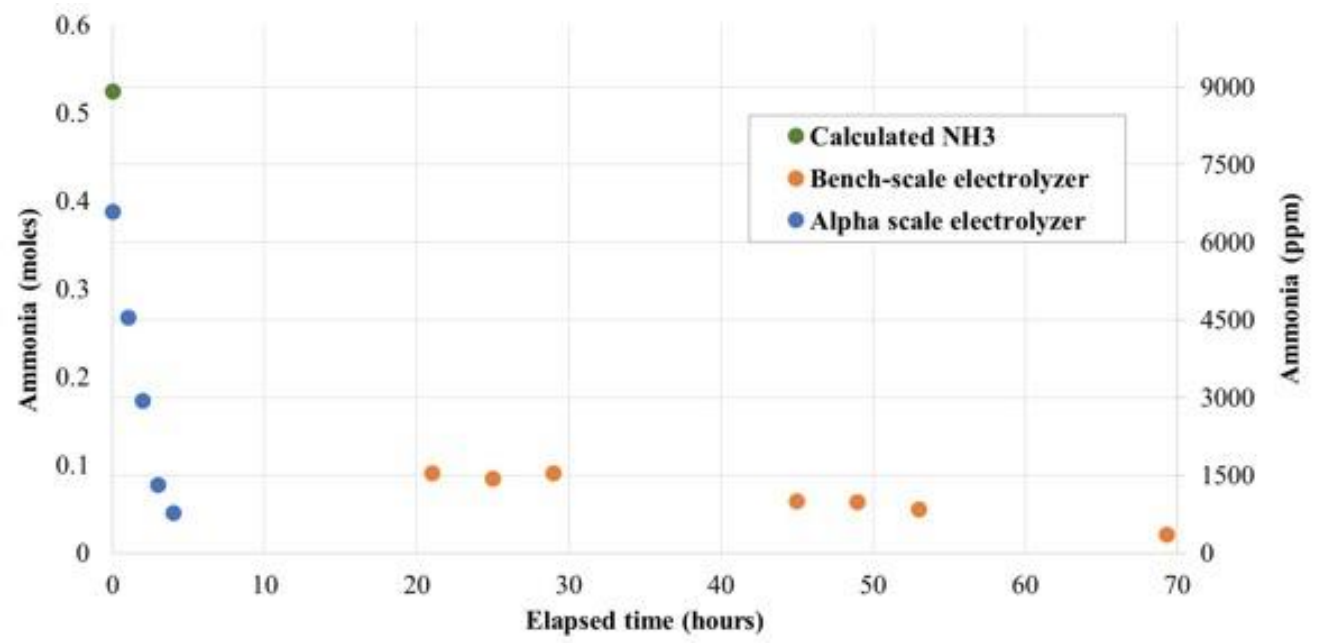

Figure 17. Ammonia concentration in ppm (right axis) determined via ISE from $50 \mathrm{~mL}$ aliquots extracted, at periodic intervals, from $1 \mathrm{~L}$ of BSHU throughout $6 \mathrm{~V}$ electrochemical conversion. The moles of ammonia (left axis) within the 1L reservoir was determined by scaling the ISE measured ammonia concentration from $50 \mathrm{~mL}$ to $1 \mathrm{~L}$.

\section{Conclusion}

A bench-scale electrochemical ammonia oxidation/destruction electrolyzer was designed, fabricated, optimized, and scaled to demonstrate the potential removing ammonia from synthetic urine simulant. The data included herein demonstrated that the ammonia reactor was able to completely remove ammonia from the synthetic urine simulant and was scalable. The best processing conditions to date will be evaluated in terms of ammonia conversion performance in zero gravity in May 2021. If successful the ammonia reactor could be incorporated within the water recovery system on board the ISS.

In future studies, we plan on to continue evaluating the alpha scale ammonia reactor to demonstrate its performance to remove ammonia from $6 \mathrm{~L}$ synthetic urine electrolyte.

\section{Acknowledgments}

The financial support of NASA Contract No. NNX17CA30P and 80NSSC18C0222 is acknowledged. 


\section{References}

${ }^{1}$ Carrasquillo, R., "ISS ECLSS Technology Evolution for Exploration," $43^{\text {rd }}$ AIAA Aerospace Sciences Meeting and Exhibit, Reno, NV, 2005, pp. 337.

${ }^{2}$ Anderson, M., Sargusingh, M., and Perry, J., "Evolution of Environmental Control and Life Support System Requirements and Assumptions for Future Exploration Missions", $47^{\text {th }}$ International Conference on Environmental Systems, Charleston, SC, 2017.

${ }^{3}$ Richardson, J., Flynn, M. T., Samson, J., and Trieu, S., "Design, Construction, and Testing of the Forward Osmosis Secondary Treatment System to Treat Bioreactor Effluent", $43^{\text {rd }}$ International Conference on Environmental Systems, Vail, CO, 2013, pp.3336.

${ }^{4}$ Shon, H. K., Vigneswaran, S., Kim, I. S., Cho, J., and Ngo, H. H., "Effect of pretreatment on thefouling of membranes: application in biologically treated sewage effluent," J. Membr. Sci., Vol. 234, No. 1-2, 2004, pp. 111120.

${ }^{5}$ Zou, S. Q., and He, Z., "Enhancing wastewater reuse by forward osmosis with self-diluted commercial fertilizers as draw solutes," Water Res., Vol. 99, 2016, pp. 235-243.

${ }^{6}$ Nicolau, E., Fonseca, J. J., Rodriguez-Martinez, J. A., Richardson, T. M. J., Flynn, M., Griebenow, K., and Cabrera, C. R., "Evaluation of a Urea Bioelectrochemical System for Wastewater Treatment Processes," ACS Sustain. Chem. Eng., Vol. 2, No. 4, 2014, pp. 749-754.

${ }^{7}$ Cabrera, C. R., and Miranda, F. A., "Advanced Nanomaterials for Aerospace Applications," Chapter 4. Pan Stanford Publishing Pte. Ltd., Singapore, 2014.

${ }^{8}$ Cardona-Vélez, W. J., Rojas-Pérez, A., Barreto-Vázquez, D., Pagán-Jiménez, A. S., Toranzos, G. A., Cabrera, C. R., Vijapur, S. H., Hall, T. D., and Taylor, E. J., "Urea Removal and Ammonia Detection Evaluation through Synthetic Urine Continuous Bio-Electrochemical Reactor for Closed Loop Environments", To Be Published in $50^{\text {th }}$ International Conference on Environmental Systems, Virtual Event, 2021.

${ }^{9}$ Carrasquillo, R. L., "Status of the Node 3 Regenerative ECLSS Water Recovery and Oxygen Generation Systems," 33rd International Conference on Environmental Systems, Vancouver, Canada, 2003.

${ }^{10}$ Holder, D. W., and Hutchens, C. F., "Development Status of the International Space Station, Urine Processor Assembly," Society of Automotive Engineers, Technical Paper, 2003.

${ }^{11}$ Schussel, L. J., and Atwater, J. E., "A Urease Bioreactor for Water Reclamation Aboard Manned Spacecraft," Chemosphere, Vol. 30, No. 5, 1995, pp. 985-994.

${ }^{12}$ Gurung, N., Ray, S., Bose, S., and Rai, V., "A Broader View: Microbial Enzymes and Their Relevance in Industries, Medicine, and Beyond," BioMed Research International, 2013.

${ }^{13}$ Zhang, J., She, Q., Chang, V. W. C., Tang, C. Y., and Webster, R. D., "Mining Nutrients (N, K, P) from Urban Source-Separated Urine by Forward Osmosis Dewatering," Environmental Sci \& Tech, Vol. 48, No. 6, 2014, pp. 3386-3394.

${ }^{14}$ Zhang, F., Brastad, K. S., and He, Z., "Integrating Forward Osmosis into Microbial Fuel Cells for Wastewater Treatment, Water Extraction and Bioelectricity Generation". Environmental Sci. \& Tech., Vol. 45, 2011, pp. 66906696.

${ }^{15}$ Martínez-Rodríguez, R. A., Vidal-Iglesias, F. J., Solla-Gullón, J., Cabrera, C. R., and Feliu, J. M., "Synthesis and Electrocatalytic Properties of $\mathrm{H}_{2} \mathrm{SO}_{4}$-Induced (100) Pt Nanoparticles Prepared in Water-in-Oil Microemulsion," ChemPhysChem, Vol. 15, 2014, pp. 1997-2001.

${ }^{16}$ Ipe, D. S. and Ulett, G. C., "Evaluation of the in vitro growth of urinary tract infection-causing gram-negative and gram-positive bacteria in a proposed synthetic human urine (SHU) medium," J. Microbiol. Methods, Vol. 127, 2016, pp. 164-171.

${ }^{17}$ Landy, M., Larkum, N. W., Oswald, E. J., "Bacterial Synthesis of p-Aminobenzoic Acid,” Experimental Biology and Medicine, Vol. 52, No. 4, 1943, pp. 338-341.

${ }^{18}$ Thermo Scientific Orion Dual Start pH/ISE user guide.

International Conference on Environmental Systems 